\title{
Protective mechanical ventilation with optimal PEEP during RARP improves oxygenation and pulmonary indexes
}

\author{
Jianwei Zhou' ${ }^{1 \dagger}$, Chuanguang Wang ${ }^{1 \dagger}$, Ran Lv², Na Liu², Yan Huang ${ }^{1}$, Wu Wang ${ }^{1}$, Lina Yu and Junran Xie ${ }^{2^{*}}$
}

\begin{abstract}
Background: This trial aimed to evaluate the effects of a protective ventilation strategy on oxygenation/pulmonary indexes in patients undergoing robot-assisted radical prostatectomy (RARP) in the steep Trendelenburg position.

Methods: In phase 1, the most optimal positive end-expiratory pressure (PEEP) was determined in 25 patients at 11 $\mathrm{CmH}_{2} \mathrm{O}$. In phase 2, 64 patients were randomized to the traditional ventilation group with tidal volume (VT) of $9 \mathrm{ml} /$ $\mathrm{kg}$ of predicted body weight (PBW) and the protective ventilation group with VT of $7 \mathrm{ml} / \mathrm{kg}$ of PBW with optimal PEEP and recruitment maneuvers (RMs). The primary endpoint was the intraoperative and postoperative $\mathrm{PaO}_{2} / \mathrm{FiO}_{2}$. The secondary endpoints were the $\mathrm{PaCO}_{2}, \mathrm{SpO}_{2}$, modified clinical pulmonary infection score (mCPIS), and the rate of complications in the postoperative period.
\end{abstract}

Results: Compared with controls, $\mathrm{PaO}_{2} / \mathrm{FiO}_{2}$ in the protective group increased after the second $\mathrm{RM}(P=0.018)$, and the difference remained until postoperative day $3(P=0.043)$. $\mathrm{PaCO}_{2}$ showed transient accumulation in the protective group after the first RM (T2), but this phenomenon disappeared with time. $\mathrm{SpO}_{2}$ in the protective group was significantly higher during the first three postoperative days. Lung compliance was significantly improved after the second RM in the protective group $(P=0.025)$. The mCPIS was lower in the protective group on postoperative day 3 (0.59 (1.09) vs. 1.46 (1.27), $P=0.010)$.

Conclusion: A protective ventilation strategy with lower VT combined with optimal PEEP and RMs could improve oxygenation and reduce mCPIS in patients undergoing RARP.

Trial registration: ChiCTR ChiCTR1800015626. Registered on 12 April 2018.

Keywords: Positive-pressure respiration, Postoperative complications, Respiration, Artificial, Robotic surgical procedures

\section{Background}

Prostate cancer is the most common cancer in men, with approximately 1,414,259 new cases and 375,304 deaths recorded in 2020 [1]. The incidence of prostate cancer is rapidly growing in Asians because of a Westernized lifestyle and improved life expectancy [2]. Prostatectomy can

\footnotetext{
*Correspondence: xie_junran@163.com

†Jianwei Zhou and Chuanguang Wang contributed equally to this work. 2Department of Anesthesia, Sir Run Run Shaw Hospital, School of Medicine, Zhejiang University, East Qingchun Road 3, Hangzhou 310016, Zhejiang, China

Full list of author information is available at the end of the article
}

achieve a curative effect in patients with prostate cancer [3], but it is a challenging operation because of the narrow confines of the pelvis, increasing the risk of positive surgical margins [4-6].

Hence, robotic techniques, particularly robot-assisted radical prostatectomy (RARP), are well-received in urological surgery due to operative precision in the confined pelvic space $[7,8]$. During the RARP operation, the patients are placed in the steep Trendelenburg position $\left(20^{\circ}-25^{\circ}\right)$ because of robot setup requirements. This position, combined with carbon dioxide $\left(\mathrm{CO}_{2}\right)$ pneumoperitoneum at

(c) The Author(s). 2021 Open Access This article is licensed under a Creative Commons Attribution 4.0 International License, which permits use, sharing, adaptation, distribution and reproduction in any medium or format, as long as you give appropriate credit to the original author(s) and the source, provide a link to the Creative Commons licence, and indicate if changes were made. The images or other third party material in this article are included in the article's Creative Commons licence, unless indicated otherwise in a credit line to the material. If material is not included in the article's Creative Commons licence and your intended use is not permitted by statutory regulation or exceeds the permitted use, you will need to obtain permission directly from the copyright holder. To view a copy of this licence, visit http://creativecommons.org/licenses/by/4.0/ The Creative Commons Public Domain Dedication waiver (http://creativecommons.org/publicdomain/zero/1.0/) applies to the data made available in this article, unless otherwise stated in a credit line to the data. 
1.6-2 $\mathrm{kPa}$, leads to an upward movement of the diaphragm, alveolar collapse, and decreased pulmonary compliance and functional residual capacity [9]. Therefore, there is an increased risk of intraoperative hypoxia and postoperative respiratory complications. In addition, most prostate cancer patients are aged and need prolonged mechanical ventilation because of the time-consuming RARP surgery, which has been defined as a risk factor for pulmonary injury [10]. Overall, perioperative anesthesia management during RARP is a challenge in respiratory care.

Currently, the mechanical ventilation strategy of lower tidal volume (VT) associated with optimal positive endexpiratory pressure (PEEP) and intermittent recruitment maneuvers (RMs) is considered to be lung-protective in some surgical procedures, not only by alleviating pulmonary over-distension but also by eliminating atelectasis [1114]. Lower VT is usually set at $4-8 \mathrm{ml} / \mathrm{kg}$ of predicted body weight (PBW) [15]. The optimal PEEP is defined as a level associated with maximum oxygenation, best dynamic compliance, and minimal dead space while preventing lung injury and adverse hemodynamic effects [16].

Previous studies assessing protective lung ventilation were mostly performed in the context of open abdominal surgery [17-20]. Haliloglu et al. [21] showed that the lung function after RARP is less impaired when using a VT of $6 \mathrm{ml} / \mathrm{kg}$ and a $6-\mathrm{cmH}_{2} \mathrm{O}$ PEEP compared with $\mathrm{CT}$ at $8 \mathrm{ml} / \mathrm{kg}$ and ZEEP. Lee et al. [22] observed that the optimal PEEP is $7 \mathrm{cmH}_{2} \mathrm{O}$ during RARP. Other studies examined different ventilation parameters during RARP [23-26] but did not assess different VT and PEEP levels. Therefore, limited data are available about the protective effect of mechanical ventilation on postoperative pulmonary function in patients undergoing RARP.

Therefore, the aims of the present study were (1) to use a decremental PEEP trial to titrate the optimal PEEP in patients undergoing RARP; and (2) to evaluate the effects of the protective ventilation strategy on oxygenation and postoperative pulmonary complications in patients undergoing RARP. The results could help prevent surgery-related morbidity, particularly in elderly patients with decreased lung function.

\section{Methods}

\section{Patients}

This was an open-label randomized controlled trial of patients planned to undergo a selective RARP between July 2017 and February 2018 (phase 1: July 2017 to midSeptember 2017; phase 2: late September 2017 to February 2018) at the Sir Run Run Shaw Hospital of Zhejiang University. The patients were selected according to the admission sequence.

The inclusion criteria were (1) preoperative diagnosis of prostate cancer, (2) planned to undergo selective RARP, (3) > 65 years of age, (4) ASA grade I-III, (5) body mass index (BMI) $18-30 \mathrm{~kg} / \mathrm{m}^{2}$, (6) operation time $>2 \mathrm{~h}$, and (7) volunteered to participate in this study and signed the informed consent form.

The exclusion criteria were (1) respiratory comorbidities (clinical evidence or history of chronic obstructive pulmonary disease, interstitial pneumopathies, asthma, or lung surgery); (2) significant cardiac dysfunction (left ventricular ejection fraction < 40\%); (3) intracranial hypertension; (4) preoperative anemia (hemoglobin < $100 \mathrm{~g} / \mathrm{L}$ ); or (5) postoperative infection excluding pneumonia.

\section{Ethical approval}

This study was approved by the Ethics Committee of Sir Run Run Shaw Hospital of Zhejiang University (Ref. 20170622-15) on June 22nd, 2017. All methods were performed in accordance with the relevant guidelines and regulations. It was registered at the Chinese Clinical Trials Register (\#ChiCTR1800015626), the registration date is $12 / 04 / 2018$.

\section{Study design}

The study was divided into two phases. In phase 1, 25 patients undergoing RARP received a recruitment maneuver (RM) and a stepwise PEEP reduction process with steps of $2 \mathrm{cmH}_{2} \mathrm{O}$ starting from $15 \mathrm{cmH}_{2} \mathrm{O}$. Pulmonary compliance, oxygenation index, dead space fraction, and $\mathrm{P}(\mathrm{A}-\mathrm{a}) \mathrm{O}_{2}$ were compared to determine the optimal PEEP. In phase 2, 64 patients were randomly allocated to two groups, including one traditional ventilation group with VT of $9 \mathrm{ml} / \mathrm{kg}$ of $\mathrm{PBW}$ and the other protective ventilation group with $\mathrm{VT}$ of $7 \mathrm{ml} / \mathrm{kg}$ of $\mathrm{PBW}$ with optimal PEEP and RMs.

\section{Anesthetic management}

All patients received general anesthesia. The patients were pretreated with midazolam $0.03 \mathrm{mg} / \mathrm{kg}$ in the holding area. After arrival in the operating room, patients were monitored with non-invasive arterial pressure, electrocardiography, pulse oximetry, and temperature. The radial artery and central venous catheters were inserted to monitor blood pressure, arterial blood gas analysis, and central venous pressure (CVP). Cardiac output (CO) and stroke volume variation (SVV) were measured through an Edwards FloTrac sensor and Vigileo monitor (Edwards Lifesciences Corporation, Irvine, CA, USA).

Induction of anesthesia was carried out after a 3-min preoxygenation with a fraction of inspired oxygen $\left(\mathrm{FiO}_{2}\right)$ of 1.0, using intravenous sufentanil $(0.3-0.6 \mu \mathrm{g} / \mathrm{kg}$ of PBW), propofol (1.5-2 mg/kg of PBW), and rocuronium $(0.6 \mathrm{mg} / \mathrm{kg}$ of PBW). PBW was calculated according to the formula: $50+0.91$ [height $(\mathrm{cm})-152.4$ ] for men [27]. After intubation using an 8-mm inner diameter endotracheal tube, anesthesia was maintained with an infusion of propofol $(150-200 \mu \mathrm{g} / \mathrm{kg} / \mathrm{min})$, titrated to 
keep a bispectral index (BIS) value of 45-55, remifentanil $(0.2-0.4 \mu \mathrm{g} / \mathrm{kg} / \mathrm{min})$, and cisatracurium $(1.5 \mu \mathrm{g} / \mathrm{kg} /$ min) as needed to keep a train-of-four (TOF) of 0 until $30 \mathrm{~min}$ before the end of the surgical suture. The patients were extubated in the operating room when BIS reached 75 , and TOF was $>0.9$.

\section{Ventilation protocol}

In phase 1 , the patients were assigned to mechanical ventilation with a VT of $7 \mathrm{ml} / \mathrm{kg}$ at a $\mathrm{FiO}_{2}$ of 0.50 , inspiratory to expiratory ratio (I:E) $1: 2$, and a respiratory rate of $14-18$ breaths/min to maintain partial pressure of end-tidal carbon dioxide $\left(\mathrm{PetCO}_{2}\right)$ between 4.7 and $6.0 \mathrm{kPa}$. After the patients were placed in the steep Trendelenburg position $\left(20^{\circ}-25^{\circ}\right)$ and $\mathrm{CO}_{2}$ pneumoperitoneum $(1.7 \mathrm{kPa})$ was established, $\mathrm{RM}$ was performed. The respiratory frequency and I:E were adjusted to 8 breaths/ min and 1:1, respectively. Meanwhile, VT was increased from $7 \mathrm{ml} / \mathrm{kg}$ in steps of $2 \mathrm{ml} / \mathrm{kg}$, and each step was maintained for three breaths until the target airway pressure $\left(40 \mathrm{cmH}_{2} \mathrm{O}\right)$ was achieved. Thereafter, the ventilator was switched back to the previous settings but with a PEEP of $15 \mathrm{cmH}_{2} \mathrm{O}$. PEEP was then reduced in steps of $2 \mathrm{cmH}_{2} \mathrm{O}$ from 15 to $5 \mathrm{cmH}_{2} \mathrm{O}$ every $10 \mathrm{~min}$ and finally in one step to zero end-expiratory pressure (ZEEP). The ventilation protocol is depicted in Fig. 1.

In phase 2, 64 patients were randomized (using a random number table) to receive either traditional or protective ventilation. The traditional ventilation setting entailed a VT of $9 \mathrm{ml} / \mathrm{kg}$ of PBW without PEEP and RMs. The protective ventilation group was set a lower VT of $7 \mathrm{ml} / \mathrm{kg}$ of PBW with optimal PEEP added RMs every half an hour. Respiratory rates in both groups were adjusted to maintain $\mathrm{PetCO}_{2}$ between 4.7 and $6.0 \mathrm{kPa}$. Other respiratory parameters were the same as in phase 1 .

In both phases, all patients received $10 \mathrm{ml} / \mathrm{kg}$ of Ringer's lactate over $15 \mathrm{~min}$ before the induction of anesthesia. SVV was used for guiding fluid management in patients, and the value was maintained below $13 \%$. Ephedrine and phenylephrine could be used adjunctively to keep the mean arterial pressure (MAP) within $20 \%$ of the pre-induction values. Consultant anesthetists were allowed to change the ventilation protocol at any time if there was any concern about patient safety.

\section{Postoperative analgesia}

After induction of anesthesia, the patients received parecoxib $40 \mathrm{mg}$ IV in the absence of contraindication. Tramadol $100 \mathrm{mg}$ was administered IV $30 \mathrm{~min}$ before

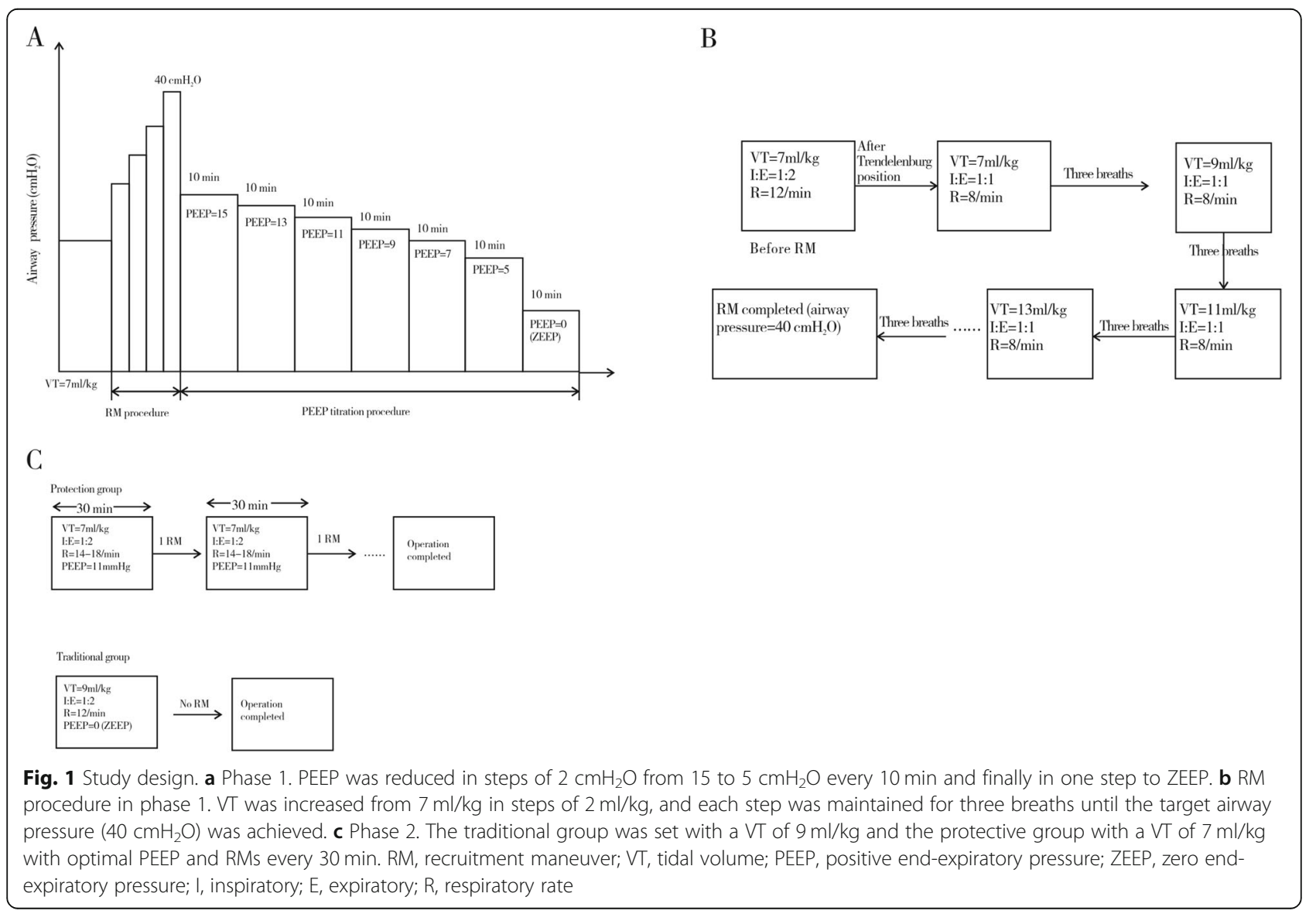




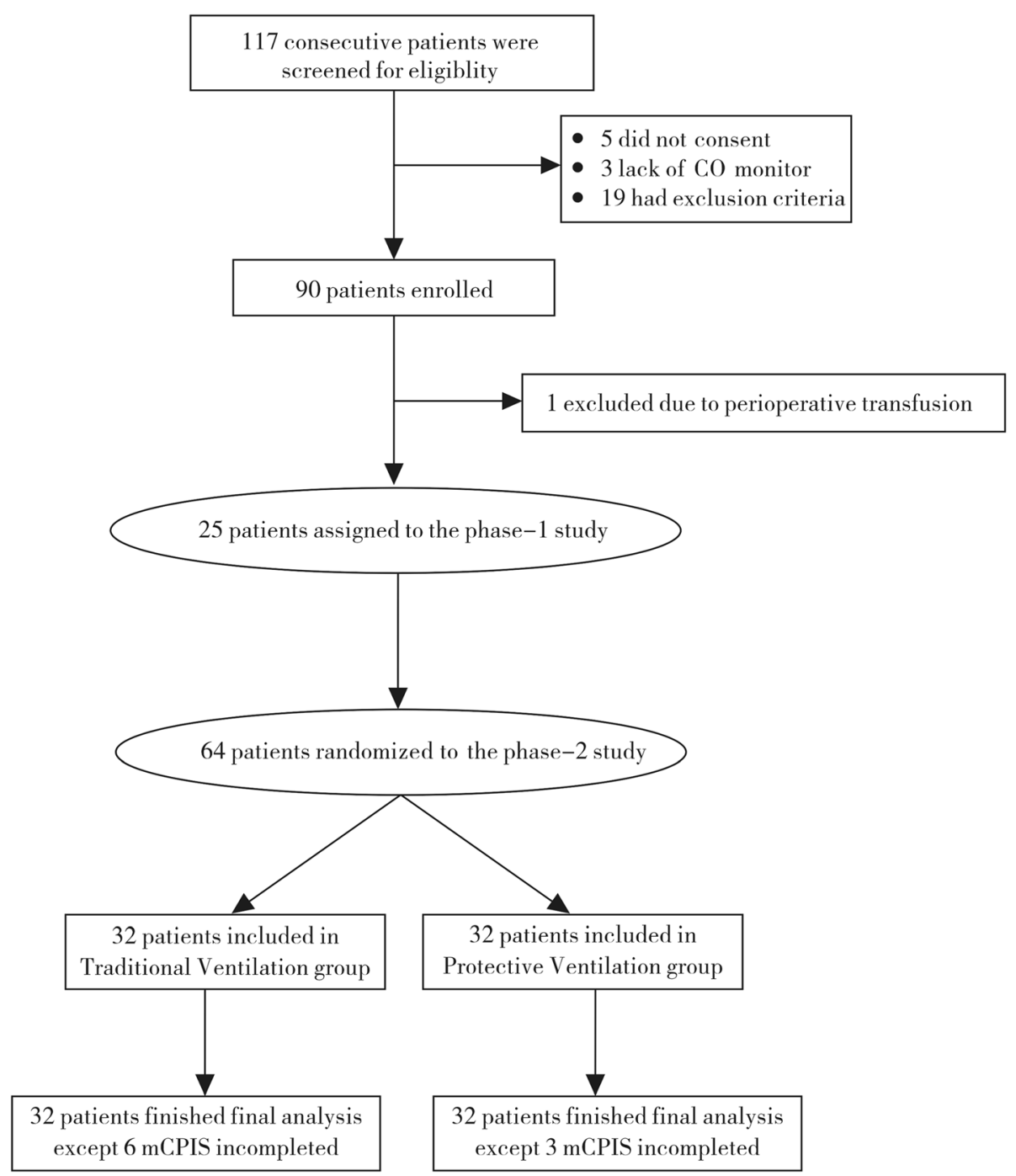

Fig. 2 Patient flowchart. CO, cardiac output; mCPIS, modified Clinical Pulmonary Infection Score

the end of surgery. A visual analog scale (VAS; 0, no pain; 10, worst possible pain) was used to evaluate pain intensity. Patients with VAS $\geq 4$ could receive painkillers. Oxycodone was titrated in the recovery room. In the ward, patients were administered parecoxib $40 \mathrm{mg}$ IV and an oral dose of tramadol $100 \mathrm{mg}$ every $12 \mathrm{~h}$.

\section{Perioperative observations}

During surgery, heart rate (HR), MAP, CVP, CO, and SVV were collected. The variables of $\mathrm{PetCO}_{2}$, PEEP, peak inspiratory pressure (PIP), and VT were recorded. The dead space fraction was defined as the ratio of physiological dead space to VT (VD/VT) and was calculated as $\mathrm{VD} / \mathrm{VT}=$ [arterial partial pressure of carbon dioxide $\left.\left(\mathrm{PaCO}_{2}\right)-\mathrm{PetCO} \mathrm{C}_{2}\right] / \mathrm{PaCO}_{2}$.

In phase 1 , arterial blood samples were collected at preoperation, post-induction of anesthesia (PA), post-
Trendelenburg position, and pneumoperitoneum (PP), 10 min after each PEEP step, and at the end of surgical suture. The parameters were obtained from the blood gas test (Blood Gas Analyzer ABL 90 FLEX, Radiometer Medical, Copenhagen, Denmark), including arterial partial pressure of oxygen $\left(\mathrm{PaO}_{2}\right), \mathrm{PaCO}_{2}$, and alveolararterial partial pressure of oxygen difference $\left[\mathrm{P}(\mathrm{A}-\mathrm{a}) \mathrm{O}_{2}\right]$. Dynamic compliance was measured using a spirometry system.

In phase 2 , the following parameters were obtained preoperatively: pulse oximetry measured oxygen saturation $\left(\mathrm{SpO}_{2}\right)$, arterial blood gas analysis in air, chest Xray, and the modified Clinical Pulmonary Infection Score (mCPIS) [18]. At the post-induction of anesthesia (T1), 20 min after each RM (T2 and T3), and 30 min after extubation (T4), the following data were collected: arterial blood gas analysis and dynamic compliance (except at 
T4). These postoperative measurements were performed on postoperative days 1, 2, and/or 3 [28]. Past day 3, no data was collected, except hospital stay.

Modified clinical pulmonary infection score (mCPIS) calculation was made by the modified original score. The postoperative pulmonary complications (PPCs) were defined as new occurrences of three or more signs: cough, increased secretions, dyspnea, chest pain, temperature $>38^{\circ} \mathrm{C}$, and $\mathrm{HR}>100$ beats min [28]. A chest X-ray was examined in a blinded way by an independent specialist in radiology who was not involved in our study. Four pathologic features were evaluated: the increased thickness of interstitium, and disventilated areas, including minimal density change, atelectasis, and pleural effusion. Postoperative follow-up was carried out by an anesthetist who was blind to the intraoperative situation. The hospital stay was finally recorded.

\section{Primary and secondary endpoints}

The primary endpoint of this study was the intraoperative and postoperative $\mathrm{PaO}_{2} / \mathrm{FiO}_{2}$. The secondary endpoints were the $\mathrm{PaCO}_{2}, \mathrm{SpO}_{2}, \mathrm{mCPIS}$, and the rate of complications in the postoperative period.

\section{Statistical analysis}

The sample size was calculated using the PASS 11.0 software (NCSS, Kaysville, UT, USA). All other statistical procedures were performed using SPSS 22.0 (IBM, Armonk, NY, USA). As a pilot study to determine the optimal mechanical ventilation parameters, the phase 1

Table 1 Perioperative characteristics of the patients

\begin{tabular}{|c|c|c|c|c|}
\hline \multirow[t]{2}{*}{ Variables } & \multirow[t]{2}{*}{ Phase $1(n=25)$} & \multicolumn{3}{|l|}{ Phase 2} \\
\hline & & Traditional ventilation $(n=32)$ & Protective ventilation $(n=32)$ & $P$ (within phase 2 ) \\
\hline Age (years) & $68.6 \pm 7.6$ & $69.9 \pm 6.8$ & $70.3 \pm 6.4$ & 0.441 \\
\hline Range & $60-84$ & $60-83$ & $60-82$ & \\
\hline Weight (kg) & $67.8 \pm 9.0$ & $64.2 \pm 9.1$ & $63.1 \pm 9.1$ & 0.242 \\
\hline BMI $\left(\mathrm{kg} / \mathrm{m}^{2}\right)$ & $23.5 \pm 2.7$ & $22.6 \pm 3.1$ & $22.5 \pm 2.6$ & 0.274 \\
\hline Range & $17.0-28.7$ & $17.1-29.9$ & $17.0-28.3$ & \\
\hline PBW (kg) & $65.2 \pm 4.5$ & $65.1 \pm 5.0$ & $62.8 \pm 5.6$ & 0.233 \\
\hline \multicolumn{5}{|l|}{ ASA grade } \\
\hline$\|$ & $24(96 \%)$ & $30(93.8 \%)$ & $30(93.8 \%)$ & 0.918 \\
\hline III & $1(4 \%)$ & $2(6.3 \%)$ & $2(6.3 \%)$ & 0.918 \\
\hline LVEF (\%) & $66.3 \pm 5.4$ & $68.5 \pm 7.3$ & $65.6 \pm 7.6$ & 0.208 \\
\hline Hypertension & $17(68 \%)$ & $18(56.3 \%)$ & $15(46.9 \%)$ & 0.280 \\
\hline Diabetes mellitus & $7(28 \%)$ & $5(15.6 \%)$ & $4(12.5 \%)$ & 0.309 \\
\hline Coronary disease & 0 & $2(6.3 \%)$ & $1(3.1 \%)$ & 0.429 \\
\hline Cerebral infarction & $1(4 \%)$ & $2(6.3 \%)$ & $1(3.1 \%)$ & 0.828 \\
\hline Smoking history & & & & 0.458 \\
\hline Never & $14(56.0 \%)$ & $23(71.9 \%)$ & $21(65.6 \%)$ & \\
\hline Former & $4(16.0 \%)$ & $3(9.4 \%)$ & $4(12.5 \%)$ & \\
\hline Current & $7(28.0 \%)$ & $6(18.7 \%)$ & $7(21.9 \%)$ & \\
\hline Operation time (min) & $184.3 \pm 64.4$ & $183.2 \pm 64.7$ & $175.4 \pm 52.6$ & 0.843 \\
\hline Postoperative hospital stay (days) & & $8.3 \pm 3.9$ & $9.3 \pm 3.7$ & 0.494 \\
\hline Estimated blood loss (ml) & $138(30-600)$ & $89(50-300)$ & $100(50-250)$ & 0.249 \\
\hline Fluids (ml) & $1790(1200-3250)$ & 1616 (1200-2800) & 1605 (1100-2250) & 0.314 \\
\hline Need for vaspressors $(n)^{\mathrm{a}}$ & $10(40 \%)$ & $12(37.5 \%)$ & $10(31.3 \%)$ & 0.772 \\
\hline Ephedrine total dose $(\mathrm{mg})^{\mathrm{b}}$ & $7.3 \pm 2.6$ & $6.6 \pm 1.9$ & $7.3 \pm 2.6$ & 0.809 \\
\hline Phenylephrine total dose $(\mathrm{ug})^{c}$ & $83.3 \pm 57.7$ & $87.5 \pm 47.9$ & $75.0 \pm 50.0$ & 0.998 \\
\hline Duration of $\mathrm{CO}_{2}$ pneumoperitoneum (min) & $135 \pm 58$ & $143 \pm 56$ & $129 \pm 43$ & 0.686 \\
\hline
\end{tabular}

BMI Body mass index, PBW Predicted body weight, ASA American Society of Anesthesiologists, LVEF Left ventricular ejection fraction

${ }^{\text {a }}$ Number of patients who received ephedrine or phenylephrine

${ }^{b}$ Ephedrine dose represents the mean from patients who received ephedrine

${ }^{c}$ Phenylephrine dose represents the mean from patients who received phenylephrine 
trial had no sample size calculation and simply included 25 patients [29]. In phase 2 , sample size calculation was performed as previously suggested [30]: $n=\left(\mathrm{Z}_{\alpha / 2}+\mathrm{Z}_{\beta}\right)^{2}$ $\times 2 \times(\text { standard deviation })^{2} /\left(\mu_{1}-\mu_{2}\right)^{2}$, where $n$ is the sample size required in each group; $\mu_{1}$ and $\mu_{2}$ are mean $\mathrm{PaO}_{2} / \mathrm{FiO}_{2}$ in the protective and traditional ventilation groups, respectively; clinically, $\mu_{1}-\mu_{2}=30 \mathrm{mmHg} ; Z_{\alpha / 2}$ reflects a $5 \%$ level of significance $(1.96) ; Z_{\beta}$ indicates an
$80 \%$ power (0.84); standard deviation was $40 \mathrm{mmHg}$. Therefore, an $n$ of 28 for each group was obtained. Considering a loss to follow-up rate of $10 \%$, a sample size of 31 per group was adopted. The normality of the distribution was tested with the Kolmogorov-Smirnov test. Data are presented as mean (SD) or median and IQR. The data were analyzed using repeated measure ANOVA, and the post hoc pair-wise comparisons were
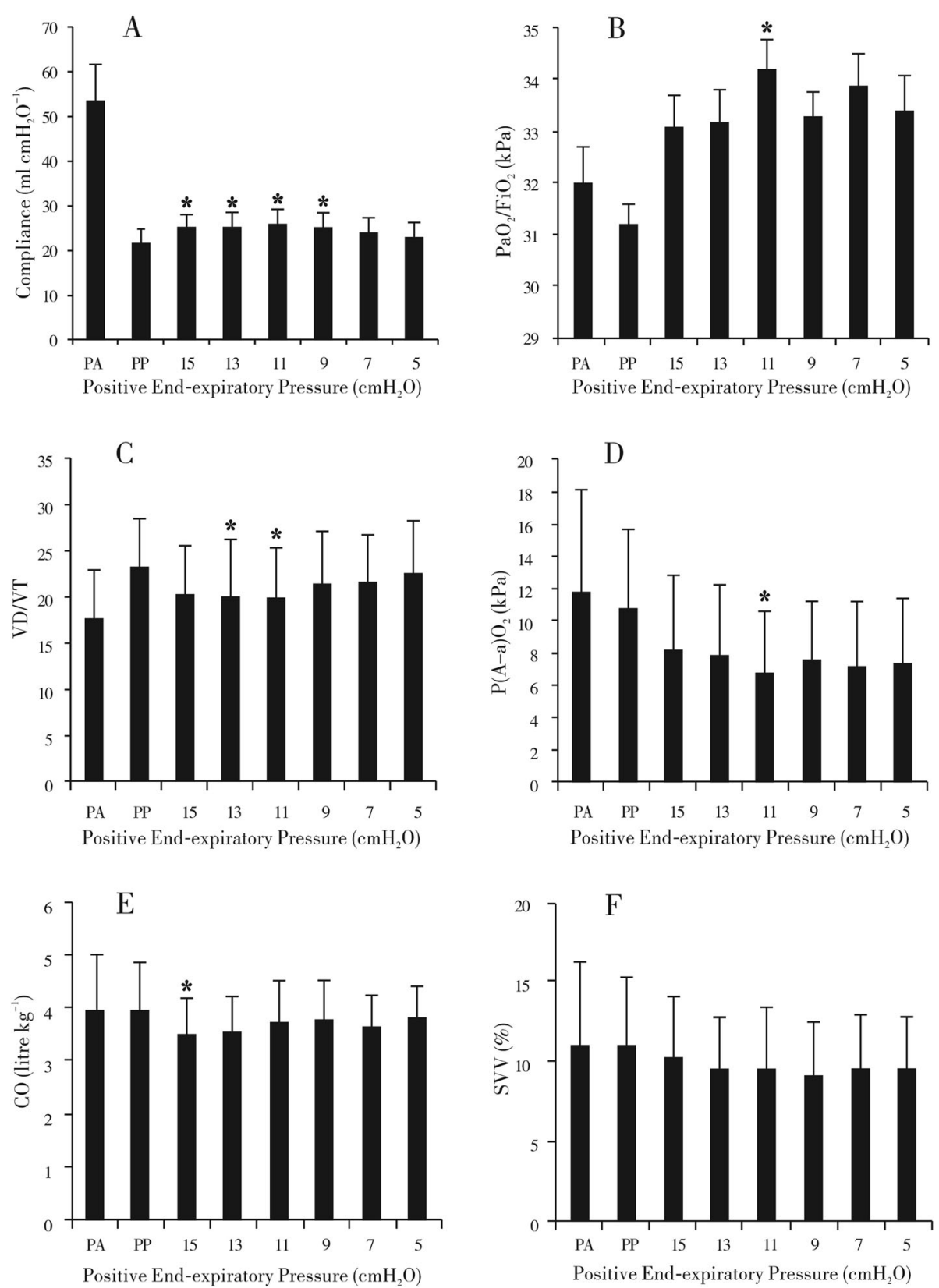

Fig. 3 Parameters of the phase 1 study, including a compliance, $\mathbf{b}$ arterial partial pressure of oxygen/fraction of inspiration $\mathrm{O}_{2}\left(\mathrm{PaO}_{2} / \mathrm{FiO}_{2}\right)$, $\mathbf{c}$ dead space volume/tidal volume (VDNT), $\mathbf{d}$ alveolar-arterial partial pressure of oxygen difference $\left(\mathrm{P}(\mathrm{A}-\mathrm{a}) \mathrm{O}_{2}\right)$, e cardiac output $(\mathrm{CO})$, and $\mathbf{f}$ stroke volume variation (SW). PA, post-induction of anesthesia; PP, pneumoperitoneum (PP); numbers on the $x$-axis, positive end-expiratory pressure (PEEP) values $\left(\mathrm{cmH}_{2} \mathrm{O}\right) .{ }^{*} P<0.05$ versus the PP group 
performed using the Tukey test or using Friedman's test (non-parametric). All tests were two-tailed, and $P<0.05$ was considered statistically significant.

\section{Results}

\section{Recruitment process}

Among 117 screened patients, 89 were finally recruited; 25 patients were assigned to the phase 1 study, and 64 were randomized in equal numbers to the two ventilation groups in the phase 2 study (Fig. 2). Except for nine subjects with incomplete mCPIS (six in the traditional group and three in the protective group; eight did not undergo X-ray because of pain, and one because the attending physician did not prescribe it), all 64 patients completed the final analysis and follow-up. Baseline characteristics are shown in Table 1.

\section{Phase 1}

In the phase 1 study, a decremental PEEP titrating trial was performed to find the optimal PEEP. Compared with the time point of $\mathrm{PP}$, the lung compliance increased significantly when the value of PEEP was adjusted to 15 $\mathrm{cmH}_{2} \mathrm{O}(P=0.014), 13 \mathrm{cmH}_{2} \mathrm{O}(P=0.012), 11 \mathrm{cmH}_{2} \mathrm{O}(P=$
0.002), or $9 \mathrm{cmH}_{2} \mathrm{O}(P=0.015)$ with the peak compliance occurring at the PEEP level of $11 \mathrm{cmH}_{2} \mathrm{O}$. In addition, $\mathrm{PaO}_{2} / \mathrm{FiO}_{2}(P=0.044)$, VD/VT $(P=0.042)$, and $\mathrm{P}(\mathrm{A}-\mathrm{a}) \mathrm{O}_{2}$ $(P=0.001)$ were also significantly improved at $11 \mathrm{cmH}_{2} \mathrm{O}$ of PEEP compared with the time point of PP. With regard to $\mathrm{CO}$ and SVV, except that $\mathrm{CO}$ was decreased at the PEEP value of $15 \mathrm{cmH}_{2} \mathrm{O}$ compared with the time point of PP $(P=0.043)$, no obvious differences were observed at other PEEP levels (Fig. 3).

\section{Phase 2}

In the phase 2 study, arterial blood analysis showed that compared with the traditional group, $\mathrm{PaO}_{2} / \mathrm{FiO}_{2}$ in the protective group apparently increased after the second RM (T3) $(P=0.018)$, and the difference remained till postoperative day $3(P=0.043) . \mathrm{PaCO}_{2}$ showed transient accumulation in the protective group after the first RM (T2), but this phenomenon disappeared with time. $\mathrm{SpO}_{2}$ in the protective group was significantly higher during the first three postoperative days (Fig. 4 and Supplementary Table 1).

The intraoperative hemodynamic and respiratory parameters are shown in Table 2. Compared with the traditional

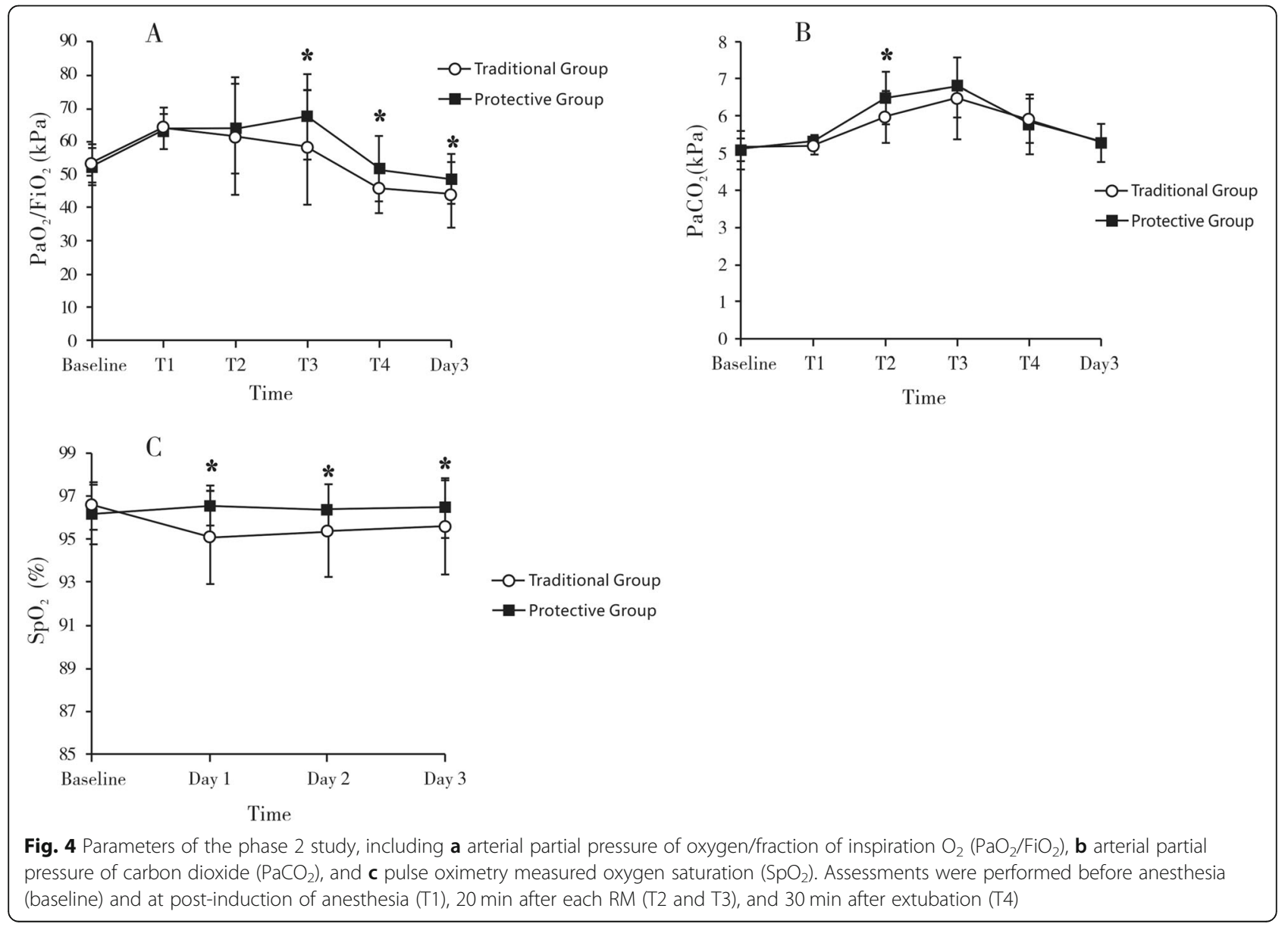


control, lung compliance was significantly improved after the second RM (T3) $(P=0.025)$ in the protective group. Meanwhile, the plateau pressure in the protective group was seemingly higher than that in the traditional group but without statistical significance $(P=0.051)$. There were no obvious hemodynamic changes with MAP, CO, and SVV in the protective group. Immediately after each RM, MAP presented transient fluctuation but remained within $\pm 20 \%$ of the pre-induction values.

The mCPIS was significantly lower in the protective group on postoperative day 3 (0.59 (1.09) vs. 1.46 (1.27), $P=0.010)$ (Table 3). The two groups differed in the chest $\mathrm{X}$-ray pathologic changes, with more patients showing normal X-ray at 3 days in the protective group $(58.6 \%$ vs. $26.9 \%, P=0.018)$. Compared with the protective group, more cases in the traditional group showed patchy or diffuse infiltration on chest X-ray. The chest X-ray on postoperative day 3 demonstrated the same result that there were more severe alterations in the traditional group, including increased thickness of interstitium, disventilated areas, and atelectasis (Table 4). With regard to PPCs, although there were more postoperative cases of cough and increased secretions in the traditional group, the occurrence of PPCs was the same in the two groups (Table 5). Finally, the hospital stay was similar (traditional group: $8.3 \pm 3.9$ days, protective group: $9.0 \pm$ 3.7 days).

\section{Discussion}

The steep Trendelenburg position and capnoperitoneum during RARP may impair the postoperative lung function. This trial aimed to evaluate the effects of a protective ventilation strategy on oxygenation and respiratory complications in patients undergoing RARP. In the first phase, a PEEP reduction trial was performed during RARP to identify the optimal PEEP of $11 \mathrm{cmH}_{2} \mathrm{O}$. In the second phase, compared to the traditional ventilation with high VT, the lung-protective strategy with lower VT, optimal PEEP, and RMs were shown to improve intraoperative and postoperative oxygenation and decrease mCPIS on postoperative day 3 .

In most studies about intraoperative protective mechanical ventilation, the level of PEEP applied was not individualized, and arbitrarily selecting a level of PEEP in different patient populations and surgical procedures would contribute to the heterogeneity of results [31]. Certainly, the level of PEEP should be selected according to the patient's particular characteristics, the particularities of the surgical approach, and patient positioning $[32,33]$. Until now, various indicators can be used to identify an optimal PEEP, including oxygen partial pressure, dead space fraction, lung dynamic compliance, ventilation pattern measured by computed tomography $(\mathrm{CT})$, and an inflection point on the pressure/volume curve (P/V) [13, 34-40]. Maisch et al. [13, 23-26]

Table 2 Intraoperative respiratory and hemodynamic parameters during the phase 2 period

\begin{tabular}{|c|c|c|c|}
\hline & Traditional ventilation $(n=32)$ & Protective ventilation $(n=32)$ & $P$ \\
\hline Respiratory rate (bpm) & $12.8 \pm 1.5$ & $16.3 \pm 1.3$ & $<0.001$ \\
\hline \multicolumn{4}{|c|}{ Lung compliance $\left(\mathrm{ml} / \mathrm{cmH}_{2} \mathrm{O}\right)$} \\
\hline $\mathrm{T} 2$ & $22.3 \pm 3.9$ & $23.3 \pm 3.6$ & 0.276 \\
\hline T3 & $21.4 \pm 3.7$ & $23.5 \pm 3.7$ & 0.025 \\
\hline \multicolumn{4}{|l|}{ Pplat $\left(\mathrm{cmH}_{2} \mathrm{O}\right)$} \\
\hline $\mathrm{T} 2$ & $26.7 \pm 3.8$ & $28.2 \pm 1.8$ & 0.051 \\
\hline T3 & $27.1 \pm 3.7$ & $28.3 \pm 1.7$ & 0.113 \\
\hline \multicolumn{4}{|l|}{ VDNT } \\
\hline $\mathrm{T} 2$ & $21.0 \pm 5.8$ & $21.9 \pm 6.8$ & 0.590 \\
\hline T3 & $22.6 \pm 5.5$ & $21.7 \pm 6.6$ & 0.555 \\
\hline \multicolumn{4}{|l|}{ MAP (kPa) } \\
\hline $\mathrm{T} 2$ & $11.8 \pm 1.3$ & $11.9 \pm 1.1$ & 0.707 \\
\hline T3 & $11.8 \pm 1.3$ & $12.0 \pm 1.3$ & 0.549 \\
\hline \multicolumn{4}{|l|}{$\mathrm{CO}(\mathrm{L} / \mathrm{min})$} \\
\hline $\mathrm{T} 2$ & $3.9 \pm 0.9$ & $3.7 \pm 0.8$ & 0.282 \\
\hline T3 & $4.1 \pm 0.9$ & $4.0 \pm 0.9$ & 0.481 \\
\hline \multicolumn{4}{|l|}{ SW (\%) } \\
\hline $\mathrm{T} 2$ & $11.2 \pm 4.0$ & $9.8 \pm 2.7$ & 0.098 \\
\hline T3 & $9.5 \pm 3.4$ & $8.6 \pm 3.4$ & 0.298 \\
\hline
\end{tabular}

bpm Beats per minute, T2 and T3 20 min after each recruitment maneuver, Pplat Plateau pressure, VD Volume of physiological dead space, VT Tidal volume, MAP Mean arterial pressure, CO Cardiac output, SVV Stroke volume variation 
Table 3 Comparison of the modified Clinical Pulmonary Infection Score (mCPIS) between the two groups of traditional ventilation and protective ventilation on preoperative day 0 and postoperative day 3

\begin{tabular}{|c|c|c|c|c|c|c|}
\hline \multirow[t]{2}{*}{ Components } & \multicolumn{3}{|l|}{ Day 0} & \multicolumn{3}{|l|}{ Day 3} \\
\hline & $\begin{array}{l}\text { Traditional ventilation } \\
(n=32)\end{array}$ & $\begin{array}{l}\text { Protective ventilation } \\
(n=32)\end{array}$ & $P$ & $\begin{array}{l}\text { Traditional ventilation } \\
(n=26)\end{array}$ & $\begin{array}{l}\text { Protective ventilation } \\
(n=29)\end{array}$ & $P$ \\
\hline \multicolumn{7}{|l|}{ Temperature $\left({ }^{\circ} \mathrm{C}\right)$} \\
\hline $36.1-38.4$ & $32(100 \%)$ & $32(100 \%)$ & $>0.99$ & $26(100 \%)$ & $29(100 \%)$ & $>0.99$ \\
\hline $38.5-38.9$ & 0 & 0 & - & 0 & 0 & - \\
\hline$\geq 39.0$ and $\leq 36.0$ & 0 & 0 & - & 0 & 0 & - \\
\hline \multicolumn{7}{|l|}{ Blood leukocytes $(/ \mu l)$} \\
\hline$\geq 4000$ and $\leq 11,000$ & 31 (96.9\%) & $32(100 \%)$ & $>0.99$ & $20(76.9 \%)$ & $26(89.7 \%)$ & 0.363 \\
\hline$<4000$ and $>11,000$ & $1(3.1 \%)$ & 0 & $>0.99$ & $6(23.1 \%)$ & $3(10.3 \%)$ & 0.363 \\
\hline \multicolumn{7}{|l|}{ Tracheal secretion } \\
\hline Few & 30 (93.8\%) & $26(81.3 \%)$ & 0.257 & $17(65.4 \%)$ & $25(86.2 \%)$ & 0.07 \\
\hline Moderate & $2(6.2 \%)$ & $6(18.7 \%)$ & 0.257 & $8(30.8 \%)$ & $4(13.8 \%)$ & 0.128 \\
\hline Large & 0 & 0 & - & $1(3.8 \%)$ & 0 & $>0.99$ \\
\hline Purulent & 0 & 0 & - & 0 & 0 & - \\
\hline \multicolumn{7}{|l|}{$\mathrm{PaO}_{2} / \mathrm{FiO}_{2}$ ratio $(\mathrm{kPa})$} \\
\hline $\begin{array}{l}>240 \text { or presence } \\
\text { of ARDS }\end{array}$ & $32(100 \%)$ & $32(100 \%)$ & $>0.99$ & $22(84.6 \%)$ & $28(96.6 \%)$ & 0.286 \\
\hline $\begin{array}{l}\leq 240 \text { and absence } \\
\text { of ARDS }\end{array}$ & 0 & 0 & - & $4(15.4 \%)$ & $1(3.4 \%)$ & 0.286 \\
\hline \multicolumn{7}{|l|}{ Chest X-ray } \\
\hline No infiltrate & $28(87.5 \%)$ & $26(81.3 \%)$ & 0.491 & $13(50.0 \%)$ & $22(75.9 \%)$ & 0.047 \\
\hline Patchy or diffuse infiltrate & $4(12.5 \%)$ & $6(18.7 \%)$ & 0.491 & $12(46.2 \%)$ & $6(20.7 \%)$ & 0.044 \\
\hline Localized infiltrate & 0 & 0 & - & $1(3.8 \%)$ & $1(3.4 \%)$ & $>0.99$ \\
\hline mCPIS & $0.27(0.67)$ & $0.41(0.73)$ & 0.449 & $1.46(1.27)$ & $0.59(1.09)$ & 0.010 \\
\hline
\end{tabular}

$\mathrm{PaO}_{2}$ Arterial partial pressure of oxygen, $\mathrm{FiO}_{2}$ Fraction of inspired oxygen, ARDS Acute respiratory distress syndrome, $m C P I S$ Modified clinical pulmonary infection score

combined best pulmonary compliance, highest oxygen partial pressure, and lowest VD/VT to determine the best PEEP of $10 \mathrm{cmH}_{2} \mathrm{O}$ in faciomaxillary surgery with healthy lungs. Therefore, in the present study, we used multiple variables together to find the optimal PEEP, including oxygen partial pressure, dead space fraction, $\mathrm{P}(\mathrm{A}-\mathrm{a}) \mathrm{O}_{2}$, and lung dynamic compliances.
In the first phase, we found that the optimal PEEP during RARP was $11 \mathrm{cmH}_{2} \mathrm{O}$. Dynamic compliance was continuously monitored during mechanical ventilation and reached the peak value when the PEEP was set at 11 $\mathrm{cmH}_{2} \mathrm{O}$. Moreover, the oxygenation index and $\mathrm{P}(\mathrm{A}-\mathrm{a}) \mathrm{O}_{2}$ were the best at PEEP of $11 \mathrm{cmH}_{2} \mathrm{O}$. Despite that the values of VD/VT were significantly decreased at PEEPs

Table 4 Results of chest X-ray test in the two groups of traditional ventilation and protective ventilation on preoperative day 0 and day 3

\begin{tabular}{|c|c|c|c|c|c|c|}
\hline & \multicolumn{3}{|l|}{ Day 0} & \multicolumn{3}{|l|}{ Day 3} \\
\hline & $\begin{array}{l}\text { Traditional ventilation } \\
(n=32)\end{array}$ & $\begin{array}{l}\text { Protective ventilation } \\
(n=32)\end{array}$ & $P$ & $\begin{array}{l}\text { Traditional ventilation } \\
(n=26)\end{array}$ & $\begin{array}{l}\text { Protective ventilation } \\
(n=29)\end{array}$ & $P$ \\
\hline Normal & $27(84.4 \%)$ & $26(81.3 \%)$ & 0.740 & 7 (26.9\%) & $17(58.6 \%)$ & 0.018 \\
\hline $\begin{array}{l}\text { Increased thickness of } \\
\text { interstitium }\end{array}$ & $3(9.4 \%)$ & $4(12.5 \%)$ & $>0.99$ & $10(38.5 \%)$ & 7 (24.1\%) & 0.251 \\
\hline $\begin{array}{l}\text { Disventilatory areas including } \\
\text { minimal density change }\end{array}$ & $2(6.2 \%)$ & $2(6.2 \%)$ & $>0.99$ & $6(23.1 \%)$ & $5(17.3 \%)$ & 0.589 \\
\hline Atelectasis & $0(0 \%)$ & 0 & - & $3(11.5 \%)$ & 0 & 0.198 \\
\hline Pleural effusions & $0(0 \%)$ & 0 & - & 0 & 0 & - \\
\hline
\end{tabular}




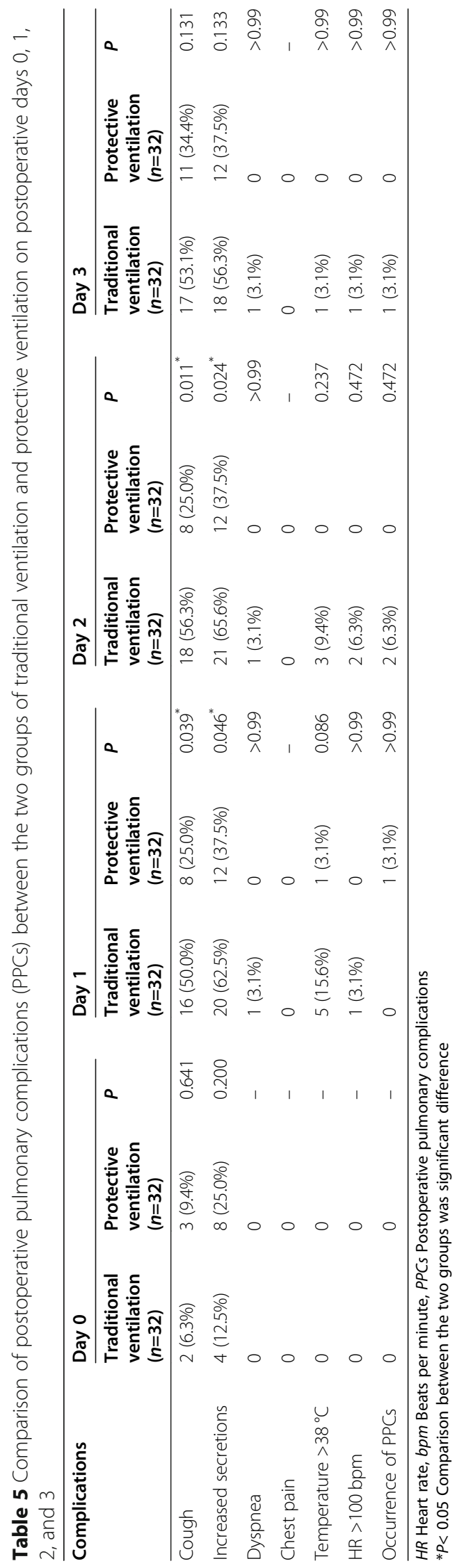


of 13 and $11 \mathrm{cmH}_{2} \mathrm{O}, 11 \mathrm{cmH}_{2} \mathrm{O}$ was finally selected as an ideal PEEP based on a cautionary principle. A high level of PEEP ( $>5 \mathrm{cmH}_{2} \mathrm{O}$ ) would cause a higher plateau pressure and more severe lung damage, but lower VT and better compliance in the protective ventilation could help neutralize the plateau pressure and decrease the risk of lung barotrauma. Nevertheless, there was no significant difference in the plateau pressure between the two groups during phase 2. Amato et al. [41] used a multilevel mediation analysis and unclosed driving pressure $(\triangle \mathrm{P}=\mathrm{VT} /$ respiratory system compliance), not PEEP or VT, was an independent variable strongly associated with survival in patients with acute respiratory distress syndrome (ARDS) and only if PEEP and VT were among the changes that led to reductions in $\Delta \mathrm{P}$ [41-43]. Alternatively, the protective ventilation approach, in which the PEEP is individualized, could result in favorable physiological effects when used intraoperatively [33, 44]. This is supported by Haliloglu et al. [21], who showed that the lung function after RARP was less impaired when using VT of $6 \mathrm{ml} / \mathrm{kg}$ and $6-\mathrm{CmH}_{2} \mathrm{O}$ PEEP compared with CT of $8 \mathrm{ml} / \mathrm{kg}$ and ZEEP, and by Lee et al. [22], who observed that the optimal PEEP was $7 \mathrm{cmH}_{2} \mathrm{O}$ during RARP.

It is demonstrated that PEEP is the most effective for optimizing lung function when an RM is performed before the application of PEEP $[10,11,45]$. RM can be performed in different ventilator ways, but most types of published RM are derived from the two basic maneuvers: a) sustained inflation maneuver and b) cycling maneuver. For example, "bag squeezing" with $40 \mathrm{cmH}_{2} \mathrm{O}$ for 40 seconds is a classical sustained inflation maneuver. Stepwise increase of VT with a constant or stepwise increase of PEEP at constant driving pressure of 15-20 $\mathrm{cmH}_{2} \mathrm{O}$ in pressure-controlled ventilation is the strategy of cycling maneuver. Considering that a sudden increase in inspiratory pressure and flow could cause high shear stress and hemodynamic instability, we chose the cycling maneuver rather than sustained inflation. When RM and high PEEP were applied, hemodynamic instability is usually an on-off problem hard to be predicted or avoided, but we did not observe any hemodynamic deterioration in the protective ventilation group. The surgery position and pneumoperitoneum increased CVP and promoted the venous return to the heart, which could counteract the increased intrathoracic pressure on hemodynamics. The doses of vasopressors were not different between the two groups, and vasopressor therapy was performed mostly after induction of anesthesia and position return.

Although PPCs were a secondary endpoint and were not included in the power analysis, the comparison of mCPIS showed that the occurrence of postoperative pulmonary infection differed between the two groups. The protective ventilation strategy with low VT, high PEEP, and RMs could improve oxygenation intraoperatively $[11,33,46]$, but it is still controversial whether PEEP with/without RMs is protective against PPCs. A metaanalysis in 2016 demonstrated that intraoperative low tidal ventilation in conjunction with PEEP and RMs reduced the occurrence of postoperative lung infection, atelectasis, and acute lung injury [46]. Similarly, another multicenter clinical study, the IMPROVE trial, advocated the use of higher PEEP levels for protective ventilation [17]. By contrast, the PROVHILO [16] and iPROVE [47] trials had no benefits of high PEEP in reducing PPCs. Moreover, intraoperative circulatory impairment induced by high PEEP was emphasized in the PROVHILO trial. During RARP with the special surgical position in our study, low VT in combination with high PEEP and RMs has been shown potential benefit for PPCs.

The study has some limitations. First, although we designed the phase 1 study to optimize PEEP in RARP, the method was not actually individualized but rather tailored to the specific conditions of RARP. The PEEP titration procedure takes one hour, which cannot be performed for all patients entering the operating room for logistics reasons. In addition, the patients were selected to be without pulmonary conditions, which introduced a bias that limits the generalizability of the results. Second, because of costs and ethics, a chest X-ray was used to evaluate the lung conditions in the present study. The difference of mCPIS between the two groups of traditional ventilation and protective ventilation on postoperative day 3 was mainly ascribed to the comparison of chest X-ray test. Compared to CT or MRI, chest X-ray may underestimate the presence of atelectasis and pulmonary morphology alterations [18]. A more accurate imaging technique should be applied. Third, the lung functions were assessed only for the first three postoperative days, while the mean hospitalization lasted 8-9 days. In addition, no follow-up lung function testing was performed. Finally, patient characteristics may influence the optimal mechanical ventilation parameters, and BMI in this study had a large variation. Due to the relatively small sample size, subgroup analyses could not be properly performed.

\section{Conclusions}

We designed a two-phase clinical trial to observe the effects of a protective ventilation strategy on oxygenation and PPCs in patients undergoing RARP. The results showed that low VT in combination with optimal PEEP (11 $\mathrm{cmH}_{2} \mathrm{O}$ ) and RMs could improve both intraoperative and postoperative oxygenation, as well as potentially reduce the occurrence of pulmonary infection. Larger clinical trials are needed to confirm whether the protective ventilation strategy could fit other events of PPCs. 


\section{Abbreviations}

RARP: Robot-assisted radical prostatectomy; PEEP: Positive end-expiratory pressure; VT: Tidal volume; PBW: Predicted body weight; CO2: Carbon dioxide; RMs: Recruitment maneuvers; RM: Recruitment maneuver: CVP: Central venous pressure; CO: Cardiac output; SW: Stroke volume variation; TOF: Train-of-four; PetCO $\mathrm{CO}_{2}$ : Pressure of end-tidal carbon dioxide; ZEEP: Xero end-expiratory pressure; MAP: Mean arterial pressure; PA: Postinduction of anesthesia; PP: Pneumoperitoneum; PPCs: Postoperative pulmonary complications

\section{Supplementary Information}

The online version contains supplementary material available at https://doi. org/10.1186/s13063-021-05310-9.

Additional file 1: Supplementary Table 1. Oxygenation parameters

during the phase 2 period.

\section{Acknowledgements}

We are thankful for the help with postoperative blood gas analysis provided by Dr. S. Yu and Dr. H. Hu (Department of Urology, Sir Run Run Shaw Hospital, Hangzhou, China). We also wish to thank Dr. X. Liu (Department of Radiology, Sir Run Run Shaw Hospital, Hangzhou, China), who kindly performed the chest X-rays.

\section{Authors' contributions}

JWZ, CGW, and JRX carried out the studies, participated in collecting data, and drafted the manuscript. YH, WW, and LNY performed the statistical analysis and participated in its design. RL and $\mathrm{NL}$ helped to draft the manuscript. The authors read and approved the final manuscript.

\section{Funding}

This study was supported by the High-level Talents Cultivating Funding Project of Lishui City (No. 2019RC03) and the Medical and Health Science and Technology Project of Zhejiang Province (2021KY413). The funding bodies have no roles in the design of the study and collection, analysis, and interpretation of data and in writing the manuscript.

\section{Availability of data and materials}

The datasets used and analyzed during the current study are available from the corresponding author on reasonable request.

\section{Declarations}

\section{Ethics approval and consent to participate}

This study was approved by the Ethics Committee of Sir Run Run Shaw Hospital of Zhejiang University (Ref. 20170622-15) on June 22nd, 2017. Al methods were performed in accordance with the relevant guidelines and regulations. They volunteered to participate in this study and signed the informed consent form.

\section{Consent for publication}

They volunteered to participate in this study and signed the informed consent form

\section{Competing interests}

The authors declare that they have no competing interests.

\section{Author details}

'Department of Anesthesia, Lishui Hospital, School of Medicine, Zhejiang University, kuocang Road 289, Lishui 323000, Zhejiang, China. ²Department of Anesthesia, Sir Run Run Shaw Hospital, School of Medicine, Zhejiang University, East Qingchun Road 3, Hangzhou 310016, Zhejiang, China ${ }^{3}$ Department of Anesthesia, the Second Affiliated Hospital, School of Medicine, Zhejiang University, Hangzhou 310009, Zhejiang, China.
Received: 24 May 2020 Accepted: 4 May 2021

Published online: 19 May 2021

\section{References}

1. The International Agency for Research on Cancer (IARC). Globocan 2020. https://gco.iarc.fr/today/data/factsheets/cancers/39-All-cancers-fact-sheet.pdf. Accessed 14 Jan 2021

2. Kimura T, Egawa S. Epidemiology of prostate cancer in Asian countries. Int J Urol. 2018:25(6):524-31. https://doi.org/10.1111/iju.13593.

3. NCCN Clinical Practice Guidelines in Oncology (NCCN Guidelines). Prostate cancer. Version 4.2019. Fort Washington: National Comprehensive Cancer Network; 2019.

4. von Bodman C, Matikainen MP, Yunis LH, Laudone V, Scardino PT, Akin O, et al. Ethnic variation in pelvimetric measures and its impact on positive surgical margins at radical prostatectomy. Urology. 2010;76(5):1092-6. https://doi.org/10.1016/j.urology.2010.02.020.

5. Marshall FF, Hortopan SC, Lakshmanan Y. Partial resection of symphysis: an aid in radical prostatectomy. J Urol. 1997;157(2):578-9. https://doi.org/10.101 6/S0022-5347(01)65208-X.

6. Kim SC, Weiser AC, Nadler RB. Resection of a posterior pubic symphyseal protuberance using the electrocautery device. Urology. 2000;55(4):586-7. https://doi.org/10.1016/S0090-4295(99)00559-2.

7. Boccon-Gibod L. Radical prostatectomy: open? Laparoscopic? Robotic? Eur Urol. 2006;49(4):598-9. https://doi.org/10.1016/j.eururo.2006.01.023.

8. Du Y, Long Q, Guan B, Mu L, Tian J, Jiang Y, et al. Robot-assisted radical prostatectomy is more beneficial for prostate cancer patients: a system review and meta-analysis. Med Sci Monit. 2018;24:272-87. https://doi.org/1 0.12659/MSM.907092.

9. Valdivieso RF, Hueber PA, Zorn KC. Robot assisted radical prostatectomy: how I do it. Part I: patient preparation and positioning. Can J Urol. 2013; 20(5):6957-61.

10. Miskovic A, Lumb AB. Postoperative pulmonary complications. Br J Anaesth. 2017;118(3):317-34. https://doi.org/10.1093/bja/aex002

11. Guldner A, Kiss T, Serpa Neto A, Hemmes SN, Canet J, Spieth PM, et al. Intraoperative protective mechanical ventilation for prevention of postoperative pulmonary complications: a comprehensive review of the role of tidal volume, positive end-expiratory pressure, and lung recruitment maneuvers. Anesthesiology. 2015;123(3):692-713. https://doi.org/10.1097/A LN.0000000000000754.

12. Unzueta C, Tusman G, Suarez-Sipmann F, Bohm S, Moral V. Alveolar recruitment improves ventilation during thoracic surgery: a randomized controlled trial. Br J Anaesth. 2012;108(3):517-24. https://doi.org/10.1093/ bja/aer415.

13. Maisch S, Reissmann H, Fuellekrug B, Weismann D, Rutkowski T, Tusman G, et al. Compliance and dead space fraction indicate an optimal level of positive end-expiratory pressure after recruitment in anesthetized patients. Anesth Analg. 2008;106:175-81 table of contents.

14. Coppola S, Froio S, Chiumello D. Protective lung ventilation during general anesthesia: is there any evidence? Crit Care. 2014;18(2):210. https://doi.org/1 $0.1186 /$ cc13777.

15. Poole J, McDowell C, Lall R, Perkins G, McAuley D, Gao F, et al. Individual patient data analysis of tidal volumes used in three large randomized control trials involving patients with acute respiratory distress syndrome. $\mathrm{Br}$ J Anaesth. 2017;118(4):570-5. https://doi.org/10.1093/bja/aew465.

16. Anaesthesiology PNIftCTNotESo, Hemmes SN, Gama de Abreu M, Pelosi P, Schultz MJ. High versus low positive end-expiratory pressure during general anaesthesia for open abdominal surgery (PROVHILO trial): a multicentre randomised controlled trial. Lancet. 2014;384:495-503.

17. Futier E, Constantin JM, Paugam-Burtz C, Pascal J, Eurin M, Neuschwander A et al. A trial of intraoperative low-tidal-volume ventilation in abdominal surgery. N Engl J Med. 2013;369(5):428-37. https://doi.org/10.1056/ NEJMoa1301082.

18. Severgnini P, Selmo G, Lanza C, Chiesa A, Frigerio A, Bacuzzi A, et al. Protective mechanical ventilation during general anesthesia for open abdominal surgery improves postoperative pulmonary function. Anesthesiology. 2013;118(6):1307-21. https://doi.org/10.1097/ALN.0b013e31 829102de.

19. Weingarten TN, Whalen FX, Warner DO, Gajic O, Schears GJ, Snyder MR et al. Comparison of two ventilatory strategies in elderly patients undergoing major abdominal surgery. Br J Anaesth. 2010;104(1):16-22. https://doi.org/10.1093/bja/aep319. 
20. Young CC, Harris EM, Vacchiano C, Bodnar S, Bukowy B, Elliott RRD, et al. Lung-protective ventilation for the surgical patient: international expert panel-based consensus recommendations. Br J Anaesth. 2019;123(6):898913. https://doi.org/10.1016/j.bja.2019.08.017.

21. Haliloglu M, Bilgili B, Ozdemir M, Umuroglu T, Bakan N. Low tidal volume positive end-expiratory pressure versus high tidal volume zero-positive endexpiratory pressure and postoperative pulmonary functions in robot-assisted laparoscopic radical prostatectomy. Med Princ Pract. 2017;26(6):573-8. https://doi.org/10.1159/000484693.

22. Lee HJ, Kim KS, Jeong JS, Shim JC, Cho ES. Optimal positive end-expiratory pressure during robot-assisted laparoscopic radical prostatectomy. Korean J Anesthesiol. 2013;65(3):244-50. https://doi.org/10.4097/kjae.2013.65.3.244.

23. Kim MS, Kim NY, Lee KY, Choi YD, Hong JH, Bai SJ. The impact of two different inspiratory to expiratory ratios (1:1 and 1:2) on respiratory mechanics and oxygenation during volume-controlled ventilation in robot-assisted laparoscopic radical prostatectomy: a randomized controlled trial. Can J Anaesth. 2015;62(9):979-87. https://doi.org/10.1007/s12630-015-0383-2.

24. Choi EM, Na S, Choi SH, An J, Rha KH, Oh YJ. Comparison of volumecontrolled and pressure-controlled ventilation in steep Trendelenburg position for robot-assisted laparoscopic radical prostatectomy. J Clin Anesth. 2011;23(3):183-8. https://doi.org/10.1016/j.jclinane.2010.08.006.

25. Ahn S, Byun SH, Chang H, Koo YB, Kim JC. Effect of recruitment maneuver on arterial oxygenation in patients undergoing robot-assisted laparoscopic prostatectomy with intraoperative $15 \mathrm{cmH} 2 \mathrm{O}$ positive end expiratory pressure. Korean J Anesthesiol. 2016;69(6):592-8. https://doi.org/10.4097/kja e.2016.69.6.592.

26. Choi ES, Oh AY, In CB, Ryu JH, Jeon YT, Kim HG. Effects of recruitment manoeuvre on perioperative pulmonary complications in patients undergoing robotic assisted radical prostatectomy: a randomised singleblinded trial. PLoS One. 2017;12(9):e0183311. https://doi.org/10.1371/journal. pone.0183311

27. Acute Respiratory Distress Syndrome N, Brower RG, Matthay MA, Morris A Schoenfeld D, Thompson BT, et al. Ventilation with lower tidal volumes as compared with traditional tidal volumes for acute lung injury and the acute respiratory distress syndrome. N Engl J Med. 2000;342:1301-8.

28. Celli BR, Rodriguez KS, Snider GL. A controlled trial of intermittent positive pressure breathing, incentive spirometry, and deep breathing exercises in preventing pulmonary complications after abdominal surgery. Am Rev Respir Dis. 1984;130(1):12-5. https://doi.org/10.1164/arrd.1984.130.1.12.

29. Almarakbi WA, Fawzi HM, Alhashemi JA. Effects of four intraoperative ventilatory strategies on respiratory compliance and gas exchange during laparoscopic gastric banding in obese patients. Br J Anaesth. 2009;102(6): 862-8. https://doi.org/10.1093/bja/aep084.

30. Liu J, Meng Z, Lv R, Zhang Y, Wang G, Xie J. Effect of intraoperative lungprotective mechanical ventilation on pulmonary oxygenation function and postoperative pulmonary complications after laparoscopic radical gastrectomy. Braz J Med Biol Res. 2019;52:e8523.

31. Kacmarek RM, Villar J. Lung-protective ventilation in the operating room: individualized positive end-expiratory pressure is needed! Anesthesiology. 2018;129(6):1057-9. https://doi.org/10.1097/ALN.0000000000002476.

32. Wirth S, Baur M, Spaeth J, Guttmann J, Schumann S. Intraoperative positive end-expiratory pressure evaluation using the intratidal compliance-volume profile. Br J Anaesth. 2015;114(3):483-90. https://doi.org/10.1093/bja/aeu385.

33. Ferrando C, Mugarra A, Gutierrez A, Carbonell JA, Garcia M, Soro M, et al. Setting individualized positive end-expiratory pressure level with a positive end-expiratory pressure decrement trial after a recruitment maneuver improves oxygenation and lung mechanics during one-lung ventilation. Anesth Analg. 2014;118(3):657-65. https://doi.org/10.1213/ANE. 0000000000000105.

34. Suarez-Sipmann F, Bohm SH, Tusman G. Volumetric capnography: the time has come. Curr Opin Crit Care. 2014;20(3):333-9. https://doi.org/10.1097/ MCC.0000000000000095.

35. Suarez-Sipmann F, Bohm SH, Tusman G, Pesch T, Thamm O, Reissmann H, et al. Use of dynamic compliance for open lung positive end-expiratory pressure titration in an experimental study. Crit Care Med. 2007;35(1):21421. https://doi.org/10.1097/01.CCM.0000251131.40301.E2.

36. Pomprapa A, Schwaiberger D, Pickerodt P, Tjarks O, Lachmann B, Leonhardt S. Automatic protective ventilation using the ARDSNet protocol with the additional monitoring of electrical impedance tomography. Crit Care. 2014; 18(3):R128. https://doi.org/10.1186/cc13937.
37. DiRocco JD, Carney DE, Nieman GF. Correlation between alveolar recruitment/derecruitment and inflection points on the pressure-volume curve. Intensive Care Med. 2007;33(7):1204-11. https://doi.org/10.1007/ s00134-007-0629-8.

38. Huang Y, Tang R, Chen Q, Pan C, Liu S, Hui X, et al. How much esophageal pressure-guided end-expiratory transpulmonary pressure is sufficient to maintain lung recruitment in lavage-induced lung injury? J Trauma Acute Care Surg. 2016;80(2):302-7. https://doi.org/10.1097/TA.0000000000000900

39. Ukere A, Marz A, Wodack KH, Trepte CJ, Haese A, Waldmann AD, et al. Perioperative assessment of regional ventilation during changing body positions and ventilation conditions by electrical impedance tomography. $\mathrm{Br} J$ Anaesth. 2016;117(2):228-35. https://doi.org/10.1093/bja/aew188.

40. Shaefi S, Eikermann M. Analysing tidal volumes early after a positive endexpiratory pressure increase: a new way to determine optimal PEEP in the operating theatre? Br J Anaesth. 2018;120(4):623-6. https://doi.org/10.1016/j. bja.2018.01.017.

41. Amato MB, Meade MO, Slutsky AS, Brochard L, Costa EL, Schoenfeld DA, et al. Driving pressure and survival in the acute respiratory distress syndrome. N Engl J Med. 2015;372(8):747-55. https://doi.org/10.1056/ NEJMsa1410639.

42. Spadaro S, Grasso S, Karbing DS, Fogagnolo A, Contoli M, Bollini G, et al. Physiologic evaluation of ventilation perfusion mismatch and respiratory mechanics at different positive end-expiratory pressure in patients undergoing protective one-lung ventilation. Anesthesiology. 2018;128(3): 531-8. https://doi.org/10.1097/ALN.0000000000002011.

43. Frank AJ, Bajwa E, Brower RG, Amato MB, Thompson BT. Inflammatory biomarkers and changes in driving pressure with positive end-expiratory pressure in acute respiratory distress syndrome. Am J Respir Crit Care Med. 2011;183:A1156

44. Ferrando C, Suarez-Sipmann F, Tusman G, Leon I, Romero E, Gracia E, et al. Open lung approach versus standard protective strategies: effects on driving pressure and ventilatory efficiency during anesthesia - a pilot, randomized controlled trial. PLoS One. 2017;12(5):e0177399. https://doi. org/10.1371/journal.pone.0177399.

45. Reinius $H$, Jonsson L, Gustafsson S, Sundbom M, Duvernoy O, Pelosi $P$, et al. Prevention of atelectasis in morbidly obese patients during general anesthesia and paralysis: a computerized tomography study. Anesthesiology. 2009;111(5):979-87. https://doi.org/10.1097/ALN.0b013e31 $81 \mathrm{~b} 87 \mathrm{edb}$.

46. Yang D, Grant MC, Stone A, Wu CL, Wick EC. A meta-analysis of intraoperative ventilation strategies to prevent pulmonary complications: is low tidal volume alone sufficient to protect healthy lungs? Ann Surg. 2016; 263(5):881-7. https://doi.org/10.1097/SLA.0000000000001443.

47. Ferrando C, Soro M, Unzueta C, Suarez-Sipmann F, Canet J, Librero J, et al. Individualised perioperative open-lung approach versus standard protective ventilation in abdominal surgery (iPROVE): a randomised controlled trial. Lancet Respir Med. 2018;6(3):193-203. https://doi.org/10.1016/S2213-2600(1 8)30024-9.

\section{Publisher's Note}

Springer Nature remains neutral with regard to jurisdictional claims in published maps and institutional affiliations.

Ready to submit your research? Choose BMC and benefit from:

- fast, convenient online submission

- thorough peer review by experienced researchers in your field

- rapid publication on acceptance

- support for research data, including large and complex data types

- gold Open Access which fosters wider collaboration and increased citations

- maximum visibility for your research: over $100 \mathrm{M}$ website views per year

At $\mathrm{BMC}$, research is always in progress.

Learn more biomedcentral.com/submissions 